\title{
Efficacy of Intravitreal Administrations of Linezolid in an Experimental Model of $S$. aureus-Related Endophthalmitis
}

\author{
Maber Saleh, ${ }^{1,2}$ Sopbie Lefèvre, ${ }^{1}$ Niyazi Acar ${ }^{3}$ Tristan Bourcier, ${ }^{2}$ Luc Marcellin, ${ }^{4}$ Gilles Prévost ${ }^{1}$ \\ Audrey Subilia, ${ }^{2}$ David Gaucher, ${ }^{2}$ and François Jehl ${ }^{1}$
}

Purpose. To evaluate the efficacy of intravitreal administration of linezolid (LZD) in a rabbit model of Staphylococcus aureus endophthalmitis.

Methods. Of 40 rabbits studied, 36 of them received $10^{2}$ colony-forming units (CFU) of $S$. aureus in their right eye before being randomly assigned to the following groups: four groups of 8 animals received 24 hours after the bacterial inoculation, 1, 10, $30 \mathrm{mg}$ of LZD (LZD 1, LZD 10, and LZD 30) or $1 \mathrm{mg}$ of vancomycin (V1), respectively. Four other animals had a sham injection in their infected eye. The 4 remaining animals were used as negative controls. Clinical, bacterial, and histologic assessments were conducted at different endpoints. Animals were euthanized at day 8 . The safety profile of intravitreal LZD was assessed by electroretinography in 5 more animals by comparing the recordings in eyes injected with 30 mg of LZD and contralateral control eyes injected with a solution of sterile saline water.

Results. At day 5, the mean inflammatory clinical scores of Nussenblatt were $7.0 \pm 1.0,3.6 \pm 0.7$, and $3.1 \pm 0.8$, in the LZD 1, LZD 10, and LZD 30 groups and $3.4 \pm 1.7$ and $7.5 \pm 0$ in the V1 and BSS + groups, respectively $(P<0.05$, ANOVA). The corresponding mean bacterial counts in the vitreous (log $10 \mathrm{CFU} / \mathrm{mL}$ ) were $6.2 \pm 6.5,3.5 \pm 3.8,0,3.8 \pm 4.2$, and $7.8 \pm$ 4.9 , respectively $(P<0.05$, ANOVA). A $30 \mathrm{mg}$ dose of LZD sterilized all the eyes at day 5 and displayed the lowest (best) histologic score $(1.5 \pm 0.6)$. Residual LZD concentrations 24 hours after the administration were between 0.1 and $7.2 \mathrm{mg} / \mathrm{L}$ LZD 30 group. The half-time of linezolid in the vitreous was 2 hours. There were no differences in the electroretinogram recordings between control eyes and eyes injected with $30 \mathrm{mg}$ of linezolid at days 1 and 14 after the intravitreal injection.

Conclusions. This is the first evidence of the effectiveness of linezolid for the treatment of experimental staphylococcal endophthalmitis. High ocular concentrations of LZD were needed to obtain a satisfactory bactericidal effect. Linezolid

From the ${ }^{1}$ Department of Microbiology, University of Strasbourg, Strasbourg, France; the ${ }^{2}$ Department of Ophthalmology, University of Strasbourg, Strasbourg, France; ${ }^{3}$ Centre National de la Recherche Scientifique, Unité Mixte de Recherche (UMR) 6265 and Institut National de la Recherche Agronomique, UMR1324, Centre des Sciences du Goût et de l'Alimentation, Dijon, France, and the Université de Bourgogne, UMR Centre des Sciences du Goût et de l'Alimentation, Dijon, France; and the ${ }^{4}$ Department of Pathology, University of Strasbourg, Strasbourg, France.

Submitted for publication August 15, 2011; revised October 20, 2011 and March 30, 2012; accepted May 21, 2012.

Disclosure: M. Saleh, None; S. Lefèvre, None; N. Acar, None; T. Bourcier, None; L. Marcellin, None; G. Prévost, None; A. Subilia, None; D. Gaucher, None; F. Jehl, None

Corresponding author: Maher Saleh, Department of Ophthalmology, University Hospital of Strasbourg, 1 place de l'hopital. 67000 Strasbourg, France; mahers_fr@yahoo.fr. displayed a concentration-dependent killing activity in the eye. Such doses of intravitreal linezolid appeared to be safe for the retinal function. (Invest Ophthalmol Vis Sci. 2012;53:48324841) DOI:10.1167/iovs.11-8417

$\mathrm{D}$ espite appropriate antibiotic treatment, bacterial endophthalmitis still frequently leads to permanent visual loss in the affected eyes.

The leading causative organisms are cocci Gram-positive, with a predominance of coagulase-negative Staphylococcus followed by Staphylococcus aureus and streptococcal species. ${ }^{1-3}$ Because the intravitreal route provides immediate and high local concentrations of the drugs, ${ }^{4}$ intravitreal injection of antibiotics (i.e., vancomycin and/or ceftazidim) is the standard therapy for Gram-positive-related endophthalmitis. However, the increasing antibiotic resistance among methicillin-resistant $S$. aureus observed in some severe infections ${ }^{5}$ has also been reported to occur in endophthalmitis isolates. ${ }^{6}$ After the emergence of vancomycin-resistant enterococci in the 1980s, significant concern existed with regard to the potential for large outbreaks of vancomycin-resistant $S$. aureus (VRSA) due to the acquisition of the vanA gene from enterococci by horizontal gene transfer. ${ }^{7}$ The vanA gene, encoded within a transposon, Tn1546, located on a plasmid, confers vanA-type vancomycin resistance in enterococci. ${ }^{8}$ However, to date, only a few cases of VRSA due to the acquisition of the vanA gene have been reported. The phenomenon of vancomycin heteroresistance in $S$. aureus (hVISA) has been reported to occur more frequently, although the best method to detect hVISA strains and their clinical significance are ill-defined. ${ }^{7}$ They have been detected globally and in many cases are associated with glycopeptide treatment failure. Sequential point mutations in key global regulatory genes seem to contribute to such VISA phenotypes.

In the case of endophthalmitis, even if the responsible Gram-positive bacteria are still susceptible to vancomycin,? sporadic cases of vancomycin resistance are emerging (endophthalmitis caused by vancomycin-resistant Enterococcus $[\mathrm{VRE}]^{10}$ ) and an elevation of the vancomycin. The minimal inhibitory concentration (MIC) within the susceptible range has been observed in coagulase-negative staphylococci isolates recovered from endophthalmitis (Pathengay A, et al. IOVS 2011;52:ARVO E-Abstract 2972). Such a development in bacterial resistance would be an issue of major concern considering that few antibiotics given by the intravitreal route provide both satisfactory antibacterial efficacy and good tolerance.

An antibiotic targeting Gram-positive bacteria and active against the agents resistant to other antibiotics would be of some interest in the management of endophthalmitis. The oxazolidinones are a recent class of synthetic antibacterial agents, the first compound of which to be commercialized was linezolid (LZD). In vitro and in vivo studies have demonstrated 
Table 1. Oxacillin, Vancomycin, and Linezolid MICs for the S. aureus Strain

\begin{tabular}{clc}
\hline \multicolumn{1}{c}{ Strain } & \multicolumn{1}{c}{ MICs $(\mathrm{mg} / \mathbf{L})$} & Susceptibility \\
\hline Staphylococcus & Oxacillin $>2$ & $\mathrm{R}$ \\
aureus (ATCC 29737) & Vancomycin $=0.5$ & $\mathrm{~S}$ \\
& Linezolid $=2$ & $\mathrm{~S}$ \\
\hline
\end{tabular}

Abbreviations: R, resistant; S, susceptible.

that linezolid has significant antimicrobial activity against Streptococcus pneumoniae, reported to be responsible for severe endophthalmitis ${ }^{11}$ and against multiresistant Grampositive pathogens such as methicillin-resistant $S$. aureus, ${ }^{12}$ and vancomycin-resistant Enterococcus (VRE). ${ }^{13}$ In addition, linezolid blocks the formation of the $70 \mathrm{~S}$ subunit, which inhibits the initiation of translation. This specific mechanism of action reduces the risk of cross-resistance with other antimicrobial agents.

Pharmacokinetics of oral, ${ }^{14-16}$ intravenous, ${ }^{17}$ and topical ${ }^{18}$ linezolid have been investigated in human and animals' noninflamed eyes. Results have demonstrated an interesting ocular penetration in both the anterior segment of the eye, and into the vitreous body. Therefore, it has been suggested that linezolid could play a role in the treatment of Gram-positiverelated endophthalmitis. ${ }^{14-16}$

However, there are no data available on the efficacy of linezolid administered in infected eyes. In this study, we compared the efficacy of intravitreal administrations of linezolid versus vancomycin, the treatment of reference in staphylococcal endophthalmitis, in an experimental model of $S$. aureus endophthalmitis.

\section{Methods}

\section{In Vivo Experimental Model of $S$. aureus Endophthalmitis}

Forty female New Zealand albino rabbits, weighing between 3 and 4 $\mathrm{kg}$, were obtained from the Animal Experimentation Service of the University of Strasbourg (Agreement number A-67-482-34). They were maintained on water and standard laboratory chow without restriction throughout the study in rooms with a controlled temperature $\left(21^{\circ} \mathrm{C}\right)$ and light cycle (12/24 hours). The animals were obtained and cared for in accordance with the recommendations of the ARVO guidelines for the Use of Animals in Ophthalmic and Visual Research (ARVO).

\section{Strain and Bacterial Preparation}

A strain of methicillin-resistant $S$. aureus was isolated from a corneal sample of a patient with a corneal keratitis and its antibiotic susceptibility and toxin profiles were determined. Classification and identification were performed using a mass spectrometry system (Microflex MALDI-BioTyper system; Bruker Daltonics, Bremen, Germany). Isolate was tested for susceptibility to oxacillin, vancomycin, and linezolid (VITEK 2 system; bioMérieux Clinical Diagnostics, Marcy l'Etoile, France). Susceptibility breakpoints and interpretive criteria were used from the 2011 recommendations of the Antibiogram Committee of the French Microbiology Society guidelines. Antimicrobial resistance testing was carried out to determine the vancomycin and linezolid MICs (Etest; bioMérieux Clinical Diagnostics) (Table 1). The mass spectrum of the $S$. aureus strain was similar to the $S$. aureus American Type Culture Collection (ATCC, Manassas, VA) 29737 reference strain, with a $\log$ score of 2.332 . The isolate was cultured for 18 hours on a $5 \%(\mathrm{wt} / \mathrm{vol})$ sheep blood agar plate, then colonies were harvested and diluted in $0.9 \%$ of $\mathrm{NaCl}(\mathrm{wt} / \mathrm{vol})$ to achieve the
TABLE 2. Animals and Treatment Regimens

\begin{tabular}{lcc}
\hline \multicolumn{1}{c}{ Group } & $\begin{array}{c}\text { Animals } \\
(\boldsymbol{n})\end{array}$ & $\begin{array}{c}\text { Intravitreal Injection } \\
(\mathbf{1 0 0} \boldsymbol{\mu L})\end{array}$ \\
\hline LZD 1 & 8 & $1 \mathrm{mg}$ of linezolid \\
LZD 10 & 8 & $10 \mathrm{mg}$ of linezolid \\
LZD 30 & 8 & $30 \mathrm{mg}$ of linezolid \\
V1 & 8 & $1 \mathrm{mg}$ of vancomycin \\
Control $+($ BSS +$)$ & 4 & Infected, treated with balanced \\
& & salt solution \\
Control $-($ BSS -$)$ & 4 & Noninfected, treated with balanced \\
& & salt solution
\end{tabular}

Three different dosages of linezolid were given (groups 1 to 3 ). The standard treatment made of $1 \mathrm{mg}$ of vancomycin was given in group 4. Two control groups were also studied.

desired bacterial count (i.e., $10^{2}$ colony-forming units [CFU] per 0.1 $\mathrm{mL}$ ). Counts were verified by plating aliquots of the serially diluted samples on 5\% (wt/vol) sheep blood agar plates, incubated overnight at $37^{\circ} \mathrm{C}$.

\section{Dosing Protocol}

Rabbits were randomly dispatched in treatment groups: four groups of 8 animals, received $10^{2}$ of $S$. aureus in their right eye. After the clinical confirmation of the insult of an endophthalmitis (i.e., red ring, conjunctival edema, bogginess of iris, or loss of red reflex), animals were treated with linezolid at different intravitreal doses: $1 \mathrm{mg}$ in group 1 (LZD 1), $10 \mathrm{mg}$ in group 2 (LZD 10), and $30 \mathrm{mg}$ in group 3 (LZD 30). Rabbits of the fourth group (V1) received $1 \mathrm{mg}$ of vancomycin, which is considered as the treatment of reference of Gram-positive bacterial endophthalmitis. A control group of 4 rabbits had their right eye infected, then injected with physiologic saline (balanced salt solution, BSS; Alcon, Ltd., Fort Worth, TX), 24 hours after the inoculum. This group constituted the positive control group (BSS+). The second control group of 4 animals received a sterile physiologic saline injection in place of the bacterial inoculum, and then received a BSS injection at 24 hours. This group was the negative control group (BSS-) (Table 2).

\section{Intravitreal Injections of Antibiotics}

Linezolid (Zyvox; Pfizer France, Paris, France) was obtained as pure titrated powder, and diluted in a sterile solution of BSS, to obtain 1, 10, and $30 \mathrm{mg}$ of LZD in a volume of $100 \mu \mathrm{L}$. Vancomycin (Vancomycine Sandoz; Sandoz SAS, Levallois-Perret, France) was prepared from an injectable powder, to get a dose of $1 \mathrm{mg}$ diluted in $100 \mu \mathrm{L}$ of BSS.

Before each intravitreal injection, rabbits were anesthetized with an intramuscular injection of a mixture of ketamine $(30 \mathrm{mg} / \mathrm{kg}$ body weight; Virbac, Carros, France) and xylazine (Rompun $2 \%, 4 \mathrm{mg} / \mathrm{kg}$ body weight; Bayer Pharma, Puteaux, France). A drop of oxybuprocaine (Oxybuprocaine Faure $1.6 \mathrm{mg} / 0.4 \mathrm{~mL}$; Novartis Pharma SAS, Rueil Malmaison, France) was instilled prior to each punction of the eye. The antibiotic was delivered 24 hours after the bacterial inoculation, through a 27-gauge needle mounted on a tuberculin syringe, introduced at $3 \mathrm{~mm}$ posterior to the limbus, into the vitreous cavity, directed toward the center of the eyeball, avoiding the crystalline lens.

\section{Clinical Investigations}

Eyes were observed clinically before and at various time points during the infection (days 1, 3, 5, and 8 after the bacterial inoculation). Clinical modifications were assessed in a masked fashion by an ophthalmologist, according to the criteria of Nussenblatt. ${ }^{19}$ Briefly, five increasing levels of severity of damage were scored for the anterior 
TABLE 3. Inflammation Was Graded in the following Ocular Structures: Cornea, Anterior Chamber, Vitreous, and Retina of Each Studied Eye

\begin{tabular}{|c|c|c|c|c|}
\hline \multirow{2}{*}{$\begin{array}{l}\text { Grade of } \\
\text { Damages } \\
\text { in Points }\end{array}$} & \multicolumn{4}{|c|}{ Histologic Parameters } \\
\hline & Cornea & Anterior Chamber & Vitreous & Retina \\
\hline 0 & $\begin{array}{l}\text { No infiltration of inflammatory } \\
\text { cells }\end{array}$ & Normal & No inflammation & Normal \\
\hline 1 & $\begin{array}{l}\text { Partial-thickness infiltration of } \\
\text { inflammatory cells }\end{array}$ & $\begin{array}{l}\text { Partially filled with fibrin; no } \\
\text { inflammatory cells }\end{array}$ & $\begin{array}{l}\text { Inflammatory cells visible; no } \\
\text { focal abscesses }\end{array}$ & $\begin{array}{l}\text { Partially infiltrated and } \\
\text { necrotic; some normal retina } \\
\text { visible }\end{array}$ \\
\hline 2 & $\begin{array}{l}\text { Segmental full-thickness } \\
\text { infiltration of inflammatory } \\
\text { cells }\end{array}$ & $\begin{array}{l}\text { Partially filled with fibrin and } \\
\text { inflammatory cells }\end{array}$ & $\begin{array}{l}\text { Partially filled with abscesses } \\
\text { and infiltrate }\end{array}$ & $\begin{array}{l}\text { Totally infiltrated and partially } \\
\text { necrotic; no normal retina }\end{array}$ \\
\hline 3 & $\begin{array}{l}\text { Total full-thickness infiltration } \\
\text { of inflammatory cells }\end{array}$ & $\begin{array}{l}\text { Completely filled with fibrin } \\
\text { and inflammatory cells }\end{array}$ & $\begin{array}{l}\text { Completely filled with } \\
\text { infiltrate }\end{array}$ & $\begin{array}{l}\text { Totally necrotic; no retina layer } \\
\text { intact }\end{array}$ \\
\hline
\end{tabular}

A score from 0 (normal) to 3 points (severely damaged) was attributed for each structure. The histologic ocular score, ${ }^{20,21}$ expressed in points (from 0 to 12), corresponded to the sum of the damage scores of each of the ocular structures.

segment and annexes (graded from 0 to 4 points) and five other levels were scored for the posterior segment ( 0 to 4 points) observed by direct ophthalmoscopy (Heine Optotechnik GmbH, Herrsching, Germany). The sum of these two scores, from 0 point (normal) to 8 points (severely damaged), constituted the ocular inflammation score of Nussenblatt.

\section{Samples Collection}

Fifty to $75 \mu \mathrm{L}$ of vitreous was aspired with a 25 -gauge needle mounted on a $2-\mathrm{mL}$ syringe, introduced at $3 \mathrm{~mm}$ of the limbus, directed toward the center of the eyeball, cautiously avoiding any bleeding. Vitreous samples were collected at day 1 to confirm the presence of an

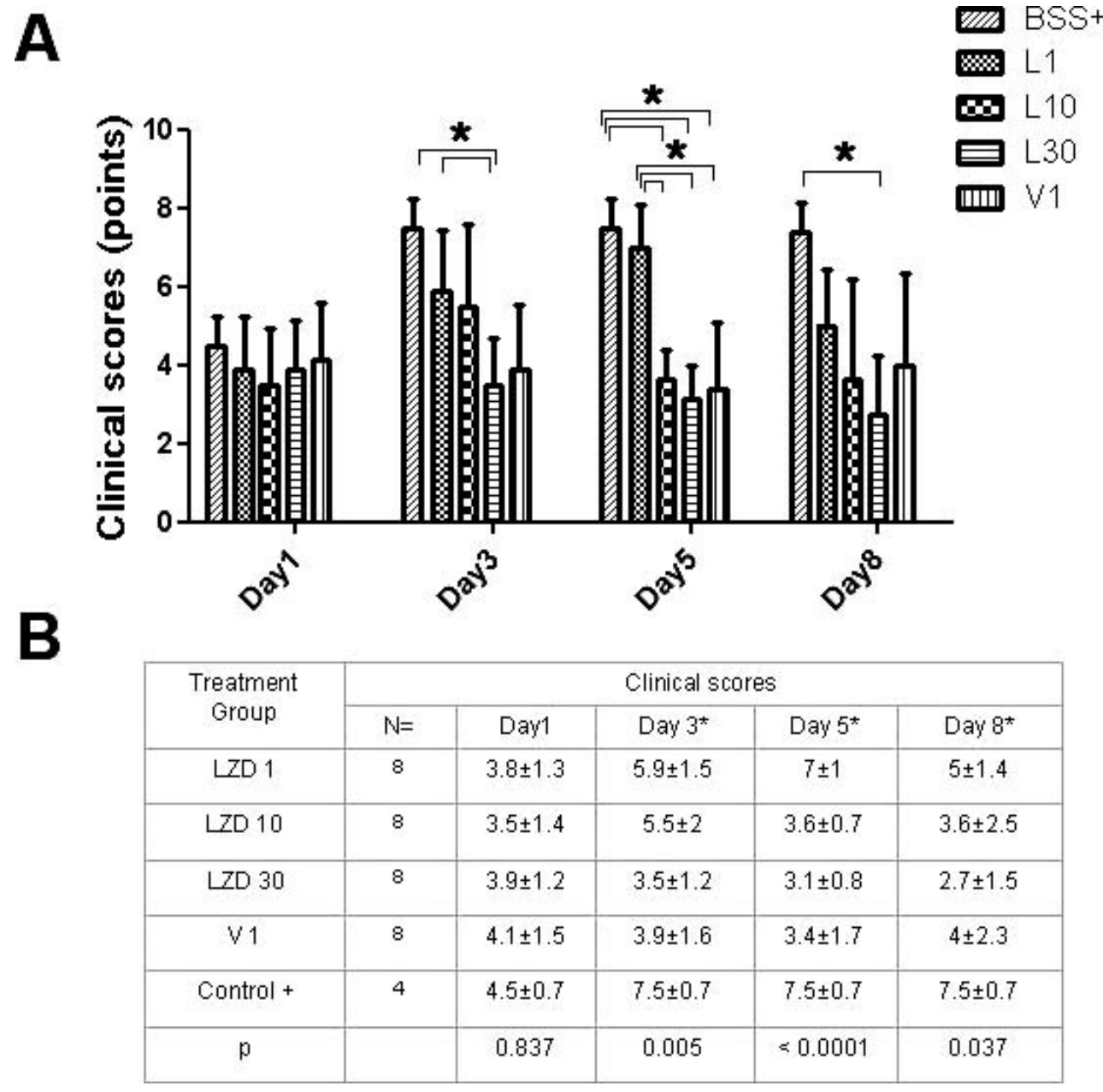

Figure 1. (A) Clinical scores corresponding to the Nussenblatt score just before the treatment (day 1), and at different time points after the treatment (days 3, 5, 8). Values are means \pm SD. Asterisk corresponds to a value of $P<0.05$ considered as significant, one-way ANOVA. (B) At day 5 , LZD 1 and the BSS + groups displayed the highest clinical scores traducing the highest damages of ocular structures. LZD 30 displayed the lower clinical scores at all endpoints and the difference was significantly different with the BSS + group $(P \leq 0.05$, one-way ANOVA, with multiple comparison test). 
A

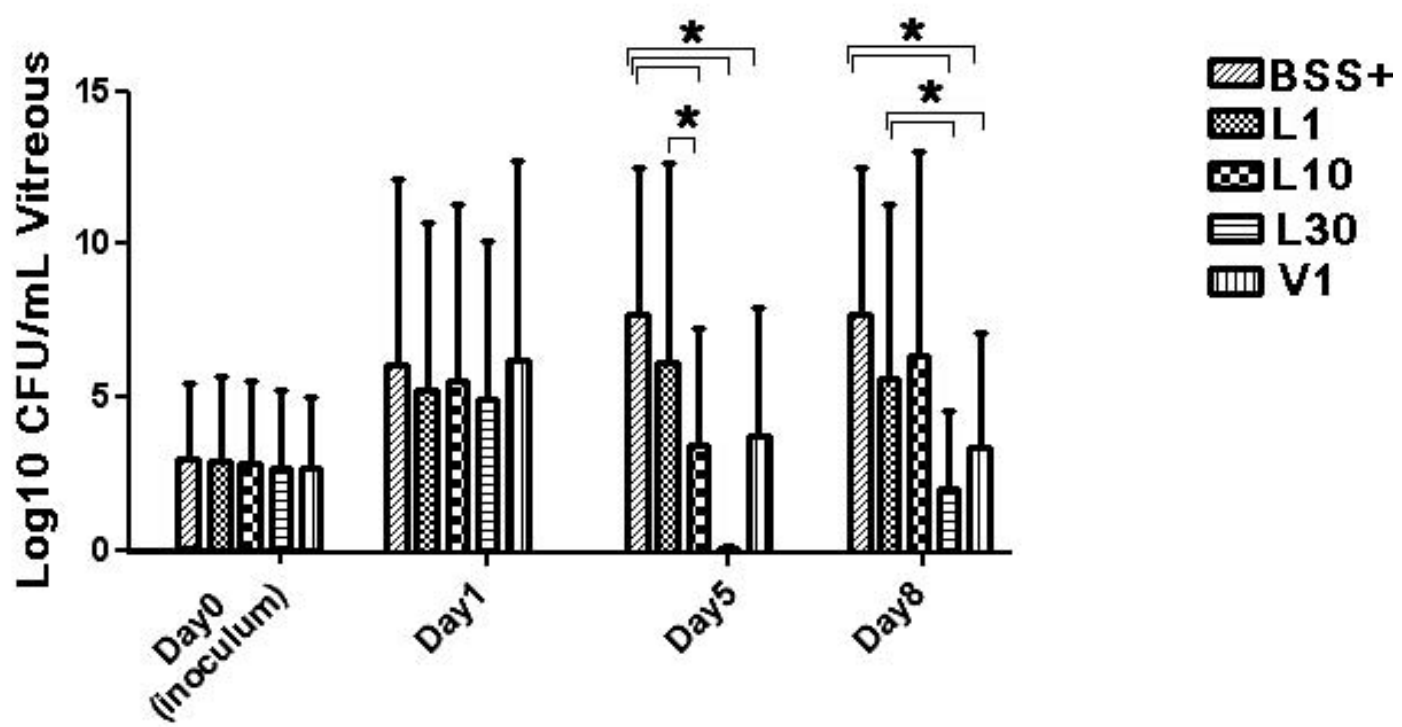

B

\begin{tabular}{|c|c|c|c|c|c|}
\hline \multirow{2}{*}{$\begin{array}{c}\text { Treatment } \\
\text { Group }\end{array}$} & \multicolumn{5}{|c|}{ Bacterial counts log10 (CFUimL) } \\
\cline { 2 - 6 } & $\mathrm{N}=$ & $\begin{array}{c}\text { Inoculum } \\
\text { (day 0) }\end{array}$ & Day 1 & Day 5 & Day 8 \\
\hline LZD 1 & 8 & $2.9 \pm 2.8$ & $5.3 \pm 5.5$ & $6.2 \pm 6.5$ & $5.7 \pm 5.7$ \\
\hline ZZD 10 & 8 & $2.8 \pm 2.7$ & $5.6 \pm 5.8$ & $3.5 \pm 3.8$ & $6.4 \pm 6.7$ \\
\hline LZD 30 & 8 & $2.7 \pm 2.5$ & $5 \pm 5.2$ & 0 & $2.1 \pm 2.5$ \\
\hline V1 & 8 & $2.7 \pm 2.3$ & $6.3 \pm 6.5$ & $3.8 \pm 4.2$ & $3.4 \pm 3.8$ \\
\hline Control & 4 & $2.9 \pm 2.5$ & $6.1 \pm 6.1$ & $7.8 \pm 4.8$ & $7.8 \pm 4.8$ \\
\hline$p$ & & 0.766 & 0.156 & $<0.0001$ & 0.021 \\
\hline
\end{tabular}

Figure 2. (A) Mean bacterial counts in the vitreous expressed in log $10 \mathrm{CFU} / \mathrm{mL}$, in control and treated eyes. Values are means \pm SD. Asterisk corresponds to $P \leq 0.05$, one-way ANOVA. (B) The multiple comparison test showed a significant decrease in bacterial counts at days 5 and 8 , in the LZD 30 and V1 groups in comparison with the LZD 1 and BSS + groups $(P<0.05)$.

endophthalmitis by a positive culture, and at day 2 to measure the residual concentrations of antibiotic 24 hours after the intravitreal administration. Samples were repeated at day 5 and at day 8 to assess the bacterial growth.

\section{Vitreous Cultures}

A $50-\mu \mathrm{L}$ aliquot was serially 10 -fold diluted in $450 \mu \mathrm{L}$ of sterile $0.9 \%$ (wt/vol) NaCl. A $100-\mu \mathrm{L}$ volume of each dilution was plated on a $5 \%$ (wt/vol) sheep blood agar plate and incubated overnight at $37^{\circ} \mathrm{C}$, to be counted after 24 hours.

\section{Histology}

Four animals from each group were euthanized with $5 \mathrm{~mL}$ sodium pentobarbital (Dolethal; Vetoquinol SA, Lure, France) given intravenously and were enucleated after the clinical scoring on day 8 . The globes were fixed in $4 \%$ buffered formaldehyde (v/v) for at least 48 hours, embedded in paraffin, and then cut in $5-\mu \mathrm{m}$-thick sections. All eyes were sectioned through the optic nerve and any gross abnormalities were recorded. Sections were stained with hematoxylin-eosin, before microscopic observation $(\times 400)$. Histologic slides were reviewed in a masked fashion by an ophthalmic pathologist and rated according to a predefined score ${ }^{20,21}$ (Table 3).

\section{Linezolid Assay}

The linezolid concentrations were determined by reverse-phase highperformance liquid chromatography (HPLC) assay, especially dedicated to eye tissues. ${ }^{22}$ The liquid chromatograph consisted of a 125 solvent delivery module (Beckman Coulter, Fullerton, CA), an injection valve (Beckman Instruments Inc., San Ramon, CA) with a loop of $20 \mu \mathrm{L}$ and a variable-wavelength detector (model 166; Beckman Coulter). Chromatograms were processed by a commercial data analysis package ( 32 Karat Software v. 5.0; Beckman Coulter). Chromatography was performed on a high-speed analytical column $(150 \times 4.6 \mathrm{~mm} \mathrm{ID})$, packed with 5 - $\mu$ m-diameter particles (UltrasphereXL-ODS; Beckman Coulter). The mobile phase consisted of $25 \mathrm{mM}$ ammonium acetateacetonitrile $(76: 24, \mathrm{v} / \mathrm{v})$, adjusted to $\mathrm{pH} 5$ with glacial acetic acid. The flow rate was set at $1.0 \mathrm{~mL} / \mathrm{min}$ and the eluent was monitored at 251 $\mathrm{nm}$. The vitreous humor was centrifuged for 10 minutes at $3000 \mathrm{~g}$, and then the supernatant was mixed with an equal volume of acetonitrile in a 5-mL screw-capped glass tube on a commercial mixer (Vortex mixer; Vortex Manufacturing Co., Cleveland, $\mathrm{OH}$ ). The resulting mixture was 


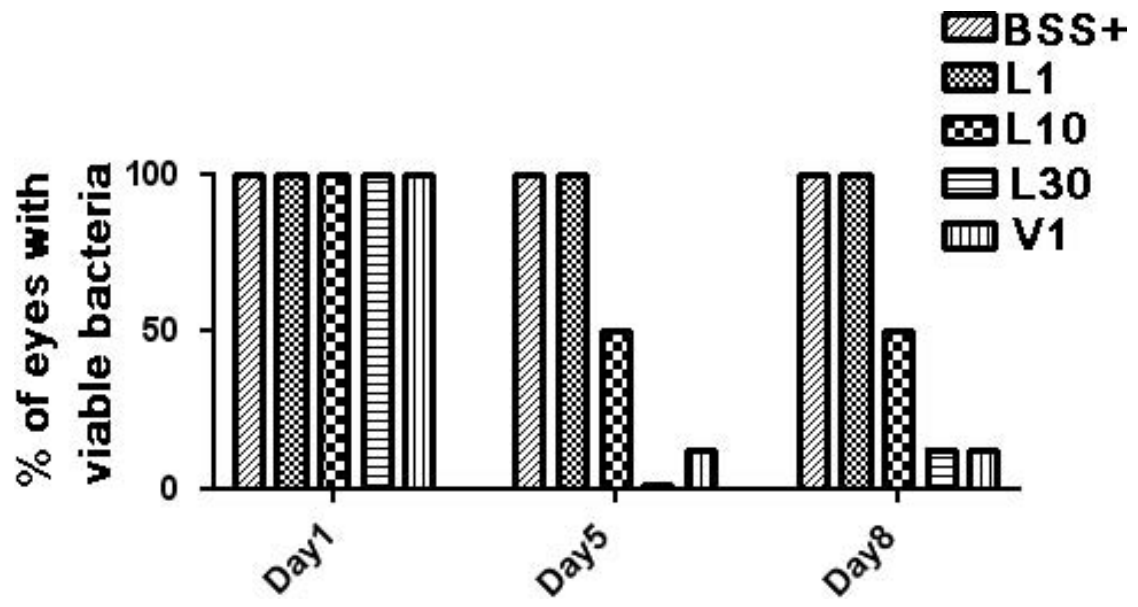

FIgURE 3. Percentage of eyes with viable bacteria from the vitreal taps at the different time points. LZD 10 sterilized half of the eyes at day 5 but a bacterial regrowth occurred in 2 eyeballs. LZD sterilized all eyes at day 5. At day 8 one regrowth was noticed in both the LZD 30 and the V1 groups.

centrifuged again for 10 minutes at $3000 \mathrm{~g} ; 20 \mu \mathrm{L}$ of the aliquot of the upper aqueous layer was injected into the HPLC column.

\section{Electroretinography}

Electroretinograms (ERGs) were recorded according to previously published procedures. ${ }^{23,24}$ Five healthy rabbits were dark-adapted overnight prior to ERG recordings. All further procedures were carried out under dim red light $(\lambda: 650 \mathrm{~nm})$. Anesthesia was induced by intramuscular injection of ketamine $(50 \mathrm{mg} / \mathrm{kg}$, Imalgène 1000; Merial, Lyon, France) and xylazine (10 mg/kg, Rompun 2\%; Bayer Pharma, Leverkusen, Germany). The pupils were dilated with $0.5 \%$ tropicamide (Ciba Vision Ophthalmics, Blagnac, France). After approximately 5 minutes, animals were positioned in a warming plate that maintained a constant body temperature, and the corneal electrodes were put in place. The ERG was recorded via corneal electrodes (thin gold wire with a 4-mm ring end); reference and ground electrodes (silver needles) were placed on the forehead and tail, respectively. The recording setup featured a Ganzfeld bowl, an amplifier, and a computer-based control and recording unit (RETI port/scan 21; Stasche \& Finger GmbH, Roland Consult, Brandenburg, Germany). ERG responses were recorded from both eyes simultaneously after the rabbits were placed in the Ganzfeld bowl. Band-pass filter width was 1 to $300 \mathrm{~Hz}$ for single-flash and flicker-stimuli recordings, which were obtained under both dark-adapted (scotopic) and light-adapted (photopic) conditions. Single-flash stimuli were presented with increasing intensities, reaching from $10^{-3}$ candelas per second per $\mathrm{m}^{2}$ (cds $\left./ \mathrm{m}^{2}\right)$ to $10 \mathrm{cds} / \mathrm{m}^{2}$, divided into six steps for scotopic ERG $\left(10^{-3}\right.$ $\mathrm{cds} / \mathrm{m}^{2}, 10^{-2} \mathrm{cds} / \mathrm{m}^{2}, 10^{-1} \mathrm{cds} / \mathrm{m}^{2}, 1 \mathrm{cds} / \mathrm{m}^{2}, 3 \mathrm{cds} / \mathrm{m}^{2}$, and $\left.10 \mathrm{cds} / \mathrm{m}^{2}\right)$, and four steps for photopic ERG $\left(3 \times 10^{-1} \mathrm{cds} / \mathrm{m}^{2}, 1 \mathrm{cds} / \mathrm{m}^{2}, 3 \mathrm{cds} / \mathrm{m}^{2}\right.$, and $10 \mathrm{cds} / \mathrm{m}^{2}$ ). Ten to 30 responses were averaged with an interstimulus interval of 5 seconds (for $10^{-3} \mathrm{cds} / \mathrm{m}^{2}, 10^{-2} \mathrm{cds} / \mathrm{m}^{2}$, $10^{-1} \mathrm{cds} / \mathrm{m}^{2}$ ) or 17 seconds (for $3 \times 10^{-1} \mathrm{cds} / \mathrm{m}^{2}, 1 \mathrm{cds} / \mathrm{m}^{2}, 3 \mathrm{cds} / \mathrm{m}^{2}$, and $10 \mathrm{cds} / \mathrm{m}^{2}$ ). Flicker stimuli had an intensity of $3 \mathrm{cds} / \mathrm{m}^{2}$ with

TABLE 4. Key Pharmacokinetic/Pharmacodynamic (PK/PD) Parameters from the Three Linezolid Groups

\begin{tabular}{lccc}
\hline Injected Dose of LZD & $\mathbf{1 ~} \mathbf{~} \mathbf{~}$ & $\mathbf{1 0} \mathbf{~} \mathbf{~ g}$ & $\mathbf{3 0 ~} \mathbf{~ m g}$ \\
\hline $\mathrm{C}_{\max }(\mathrm{mg} / \mathrm{L})$ & 666.6 & $6,700.6$ & 20,003 \\
$\mathrm{C}_{24 \mathrm{~h}}(\mathrm{mg} / \mathrm{L}), n=4$ & 0.1 & 1.1 & 7.2 \\
Vitreous half-life (h) & 1.89 & 1.91 & 2.09 \\
$t>\mathrm{MIC}(\%)$ & 65.8 & 92.9 & 100 \\
AUC $_{24 \mathrm{~h}} / \mathrm{MIC}(\mathrm{mg} / \mathrm{L} \cdot \mathrm{h})$ & 3999.5 & $39,999.6$ & 119,958 \\
\hline
\end{tabular}

Mean vitreous volume of $1.5 \pm 0.3 \mathrm{~mL}$. frequencies of $1,5,15$, and $30 \mathrm{~Hz}$. Light-adaptation was performed with a background illumination of $25 \mathrm{~cd} / \mathrm{m}^{2}$ presented for 3 minutes, to reach a stable level of the photopic response. The oscillatory potentials (OPs) were recorded prior to photopic ERG at a stimulus intensity of $10 \mathrm{cds} / \mathrm{m}^{2}$ and using a band-pass filter width of 200 to 500 Hz.

Immediately after the first ERG recording, right eyes were injected with $30 \mathrm{mg}$ of LZD $(100 \mu \mathrm{L})$ and the left eyes, which served as control eyes, received an intravitreal injection of sterile physiologic salt solution $(100 \mu \mathrm{L})$. ERG recordings were renewed 1 day and 14 days after the intravitreal injections.

\section{Statistical Analysis}

All values represent the mean \pm SD for $\geq 4$ eyes per time point assayed unless otherwise specified. For the histologic score, all values represent the mean \pm SD for 4 eyes. Descriptive statistics and onetailed ANOVA, assuming equal $(n \geq 5)$ or unequal $(n<5)$ variance, were used for statistical comparisons between groups. $P \leq 0.05$ was considered significant. A Tukey-Kramer multiple comparisons test was performed if the value of $P$ was less than 0.05 . Statistics were calculated by using a commercial data analysis package (GraphPad InStat; GraphPad Software, Inc., San Diego, CA).

\section{Results}

\section{Antistaphylococcal Efficacy}

All eyes that received a bacterial inoculum developed an acute endophthalmitis, clinically observed after 24 hours. There was

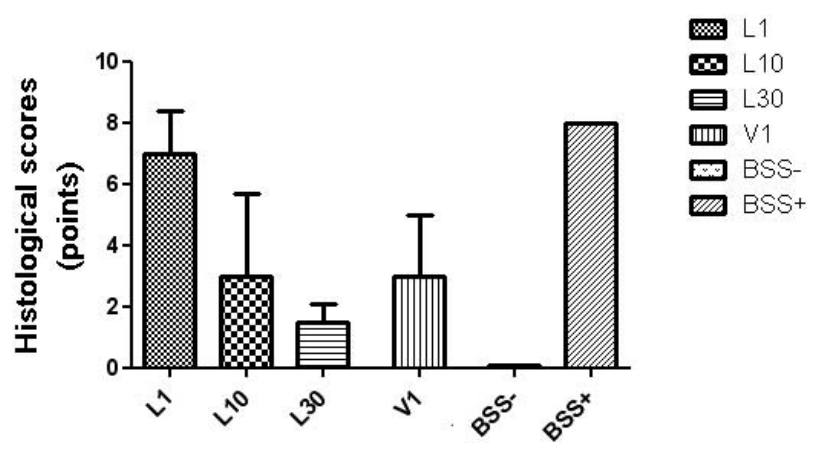

Figure 4. Histologic scores expressed in points. LZD 30 displayed the most conserved ocular anatomical features. 

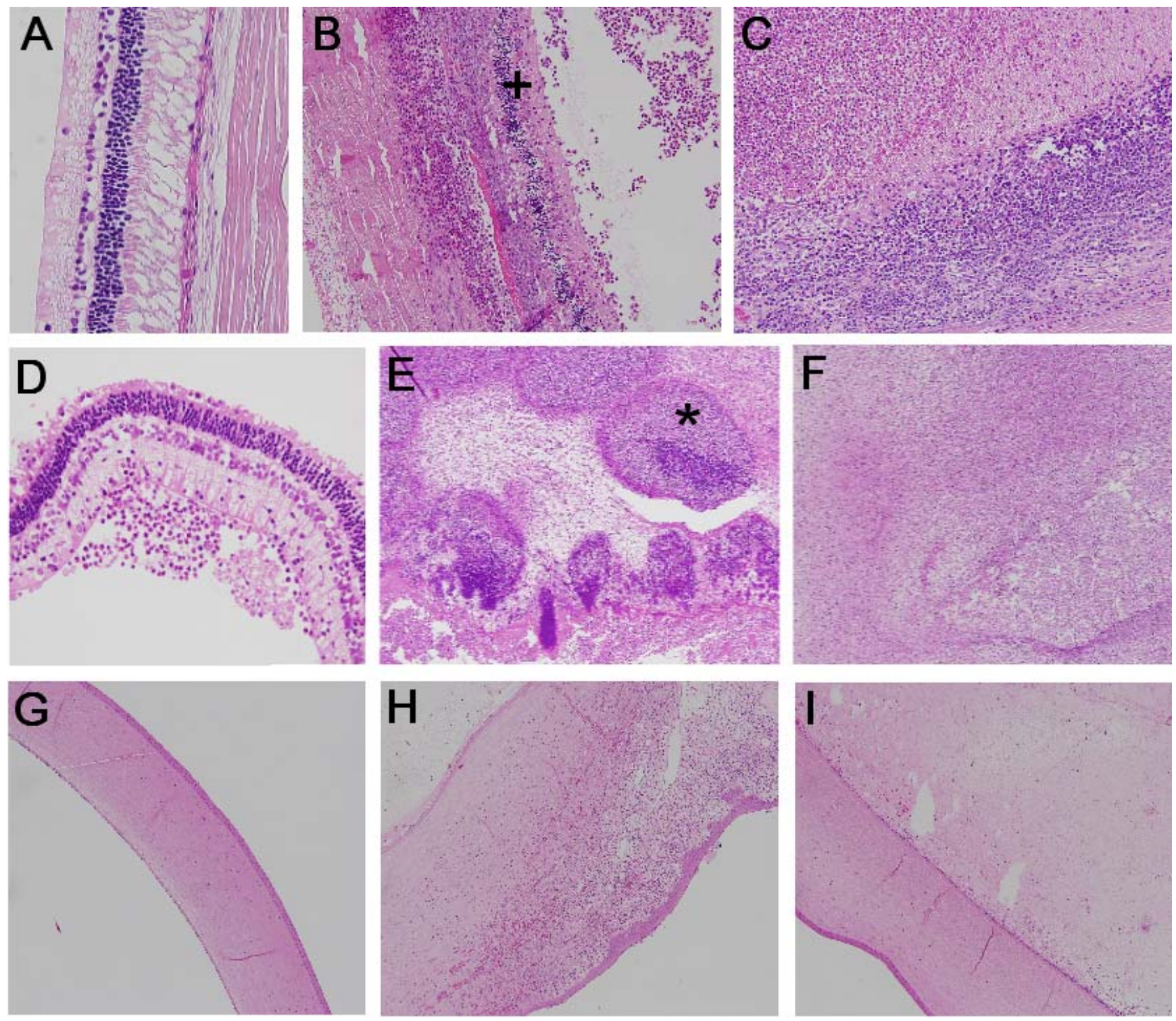

FiguRE 5. Optic microscopy pictures of hematoxylin-eosin-stained rabbit retina slides (x100 and $\mathrm{x} 400$ ). The corresponding treatment groups are enclosed in brackets. (A) Normal aspect of the retina with an empty vitreous (BSS-). (B) Partially infiltrated and necrotic retina, but some layers are seen (cross) (LZD 10). (C) Totally infiltrated and necrotic retina without any intact retinal layer and with a vitreous filled with inflammatory cells (LZD 1). (D) Some isolated inflammatory cells are visible in the vitreous (LZD 30). (E) Basophilic focal abscesses are found in the vitreous (asterisk) (BSS+). (F) Vitreous completely filled with infiltrate (LZD 1). (G) Normal aspect of the cornea (BSS-). (H) Cornea partially infiltrated with inflammatory cells (LZD 10). (I) Anterior chamber completely filled with fibrin; some inflammatory cells are present (LZD 1). Intravitreal administration of 1, 10, and $30 \mathrm{mg}$ of LZD (LZD 1, LZD 10, LZD 30, respectively). Administration of the treatment of reference made of $1 \mathrm{mg}$ of vancomycin (V1). Positive control group (BSS+) and negative control group (BSS-).

no significant difference in the size of the injected bacterial inoculum at day $0(P>0.05)$. At day 1 , just before the antibiotic intravitreal administration, groups were comparable in terms of clinical scores $(P>0.05)$ (Fig. 1) and bacterial counts $(P>0.05)$ from the vitreous of eyes infected with $S$. aureus (Fig. 2).

A $1 \mathrm{mg}$ intravitreal injection of linezolid appeared to be ineffective in treating the endophthalmitis: neither the clinical score (Fig. 1) nor bacterial count in the vitreous (Fig. 2) was significantly different from those of the BSS + group $(P>0.05)$. In addition, none of the eyes was sterilized at any time point in this group (Fig. 3).

The $10 \mathrm{mg}$ dose of linezolid produced a mixed effect: at day 5 , it reduced the bacterial count compared with the LZD 1 and the BSS + group $(P<0.05)$ and half of the eyes were sterilized (Fig. 3). However, at day 8 a bacterial regrowth was noticed in $2 / 8$ eyes and the bacterial count in this group was no longer different from the ones of the LZD 1 and BSS + groups $(P>$ 0.05) (Fig. 2). Clinical scores of LZD 10 (Fig. 1), which improved at day 5 compared with those of LZD 1 and BSS $+(P$ $<0.001)$ were no longer different from these groups at day 8 $(P>0.05)$ (Fig. 1).

The intravitreal Injection of $30 \mathrm{mg}$ of linezolid demonstrated the most potent antistaphylococcal activity. The clinical features improved significantly compared with LZ1 and BSS+ groups at days 5 and $8(P<0.001)$ (Fig. 1). However, there was no difference in clinical scores with the V1 group. At days 5 and 8 , a decrease in the bacterial count of the LZD 30 group 
TABLe 5. ERG a- and b-Wave Amplitudes and Latencies Recorded in Scotopic and Photopic Conditions Prior to and after LZD Treatment

\begin{tabular}{|c|c|c|c|c|c|c|c|}
\hline & \multirow{2}{*}{$\begin{array}{l}\text { Stimulus } \\
\text { Intensity }\end{array}$} & \multicolumn{2}{|c|}{ Before Treatment } & \multicolumn{2}{|c|}{1 Day Post-treatment } & \multicolumn{2}{|c|}{14 Days Post-treatment } \\
\hline & & Contralateral & LZD-Treated & Contralateral & LZD-Treated & Contralateral & LZD-Treated \\
\hline \multicolumn{8}{|l|}{ Scotopic a-wave } \\
\hline \multirow[t]{3}{*}{ Amplitude $(\mu \mathrm{V})$} & $1,000 \mathrm{mcds} / \mathrm{m}^{2}$ & $24.2 \pm 5.4$ & $30.7 \pm 5.4$ & $31.2 \pm 10.9$ & $28.4 \pm 7.6$ & $33.3 \pm 6.9$ & $28.1 \pm 3.8$ \\
\hline & $3,000 \mathrm{mcds} / \mathrm{m}^{2}$ & $36.6 \pm 21.8$ & $35.6 \pm 4.8$ & $39.9 \pm 10.4$ & $37.1 \pm 11.0$ & $41.4 \pm 8.9$ & $40.5 \pm 6.7$ \\
\hline & $10,000 \mathrm{mcds} / \mathrm{m}^{2}$ & $40.2 \pm 7.3$ & $45.0 \pm 7.8$ & $47.8 \pm 15.6$ & $43.6 \pm 12.1$ & $44.0 \pm 4.7$ & $44.0 \pm 8.1$ \\
\hline \multirow[t]{3}{*}{ Latency (ms) } & $1,000 \mathrm{mcds} / \mathrm{m}^{2}$ & $14.0 \pm 1.4$ & $13.6 \pm 0.8$ & $14.8 \pm 0.4$ & $14.4 \pm 0.8$ & $14.6 \pm 0.8$ & $14.8 \pm 0.8$ \\
\hline & $3,000 \mathrm{mcds} / \mathrm{m}^{2}$ & $11.4 \pm 1.6$ & $12.0 \pm 3.0$ & $12.8 \pm 1.1$ & $12.0 \pm 1.0$ & $12.8 \pm 1.1$ & $12.0 \pm 1.5$ \\
\hline & $10,000 \mathrm{mcds} / \mathrm{m}^{2}$ & $10.4 \pm 0.5$ & $11.4 \pm 11.6$ & $11.6 \pm 0.8$ & $11.0 \pm 0.7$ & $11.6 \pm 1.5$ & $11.6 \pm 1.5$ \\
\hline \multicolumn{8}{|l|}{ Scotopic b-wave } \\
\hline \multirow[t]{6}{*}{ Amplitude $(\mu \mathrm{V})$} & $1 \mathrm{mcds} / \mathrm{m}^{2}$ & $9.6 \pm 7.4$ & $9.8 \pm 4.9$ & $7.6 \pm 2.7$ & $11.9 \pm 4.6$ & $9.8 \pm 5.2$ & $11.0 \pm 5.1$ \\
\hline & $10 \mathrm{mcds} / \mathrm{m}^{2}$ & $65.3 \pm 24.6$ & $59.5 \pm 23.4$ & $60.3 \pm 7.2$ & $62.3 \pm 2.6$ & $60.5 \pm 10.5$ & $69.5 \pm 12.7$ \\
\hline & $100 \mathrm{mcds} / \mathrm{m}^{2}$ & $86.3 \pm 30.1$ & $84.8 \pm 21.4$ & $83.3 \pm 8.6$ & $81.5 \pm 7.8$ & $80.4 \pm 8.4$ & $79.2 \pm 13.4$ \\
\hline & $1,000 \mathrm{mcds} / \mathrm{m}^{2}$ & $100.5 \pm 38.5$ & $99.9 \pm 41.5$ & $102.1 \pm 22.5$ & $100.2 \pm 15.4$ & $101.7 \pm 30.5$ & $105.1 \pm 11.8$ \\
\hline & $3,000 \mathrm{mcds} / \mathrm{m}^{2}$ & $99.5 \pm 29.5$ & $107 . \pm 38.8$ & $101.7 \pm 9.5$ & $104.6 \pm 8.9$ & $102.1 \pm 14.1$ & $105.1 \pm 15.9$ \\
\hline & $10,000 \mathrm{mcds} / \mathrm{m}^{2}$ & $108.3 \pm 39.8$ & $104.8 \pm 19.2$ & $99.5 \pm 9.9$ & $109.2 \pm 6.9$ & $117.3 \pm 16.8$ & $108.1 \pm 12.4$ \\
\hline \multirow[t]{6}{*}{ Latency (ms) } & $1 \mathrm{mcds} / \mathrm{m}^{2}$ & $61.6 \pm 1.5$ & $63.2 \pm 2.3$ & $62.2 \pm 5.0$ & $61.0 \pm 4.4$ & $74.6 \pm 16.4$ & $62.0 \pm 6.9$ \\
\hline & $10 \mathrm{mcds} / \mathrm{m}^{2}$ & $55.4 \pm 4.5$ & $55.2 \pm 6.0$ & $53.6 \pm 3.3$ & $55.8 \pm 4.2$ & $55.2 \pm 4.9$ & $56.6 \pm 4.3$ \\
\hline & $100 \mathrm{mcds} / \mathrm{m}^{2}$ & $37.2 \pm 2.2$ & $36.0 \pm 1.5$ & $36.4 \pm 1.9$ & $37.0 \pm 1.0$ & $36.8 \pm 1.4$ & $38.2 \pm 3.9$ \\
\hline & $1,000 \mathrm{mcds} / \mathrm{m}^{2}$ & $34.8 \pm 2.3$ & $34.8 \pm 1.9$ & $35.4 \pm 1.5$ & $34.6 \pm 1.8$ & $36.2 \pm 1.7$ & $35.2 \pm 5.7$ \\
\hline & $3,000 \mathrm{mcds} / \mathrm{m}^{2}$ & $34.2 \pm 3.4$ & $34.8 \pm 4.1$ & $34.4 \pm 1.5$ & $34.2 \pm 3.1$ & $33.4 \pm 0.8$ & $34.8 \pm 1.7$ \\
\hline & $10,000 \mathrm{mcds} / \mathrm{m}^{2}$ & $33.4 \pm 2.0$ & $33.6 \pm 2.1$ & $33.2 \pm 1.4$ & $33.8 \pm 1.7$ & $33.6 \pm 0.5$ & $34.0 \pm 7.9$ \\
\hline \multicolumn{8}{|l|}{ Photopic b-wave } \\
\hline \multirow[t]{4}{*}{ Amplitude $(\mu \mathrm{V})$} & $300 \mathrm{mcds} / \mathrm{m}^{2}$ & $12.1 \pm 15.2$ & $11.4 \pm 15.6$ & $11.3 \pm 3.3$ & $14.5 \pm 7.7$ & $12.9 \pm 7.0$ & $13.0 \pm 4.9$ \\
\hline & $1,000 \mathrm{mcds} / \mathrm{m}^{2}$ & $22.3 \pm 12.4$ & $33.8 \pm 10.4$ & $25.1 \pm 3.9$ & $21.7 \pm 7.4$ & $22.8 \pm 6.2$ & $21.1 \pm 5.9$ \\
\hline & $3,000 \mathrm{mcds} / \mathrm{m}^{2}$ & $61.0 \pm 21.7$ & $53.8 \pm 15.9$ & $53.6 \pm 6.1$ & $55.8 \pm 14.7$ & $55.7 \pm 17.1$ & $67.1 \pm 25.5$ \\
\hline & $10,000 \mathrm{mcds} / \mathrm{m}^{2}$ & $59.5 \pm 10.3$ & $56.2 \pm 13.0$ & $60.9 \pm 4.6$ & $60.7 \pm 12.2$ & $60.3 \pm 12.6$ & $65.0 \pm 23.1$ \\
\hline \multirow[t]{4}{*}{ Latency (ms) } & $300 \mathrm{mcds} / \mathrm{m}^{2}$ & $35.2 \pm 7.4$ & $37.2 \pm 8.1$ & $34.8 \pm 2.2$ & $34.6 \pm 3.7$ & $32.8 \pm 1.3$ & $34.0 \pm 3.1$ \\
\hline & $1,000 \mathrm{mcds} / \mathrm{m}^{2}$ & $27.6 \pm 4.7$ & $28.4 \pm 6.1$ & $28.2 \pm 2.2$ & $29.4 \pm 3.7$ & $29.8 \pm 2.9$ & $29.8 \pm 0.8$ \\
\hline & $3,000 \mathrm{mcds} / \mathrm{m}^{2}$ & $29.0 \pm 1.7$ & $29.8 \pm 1.4$ & $29.0 \pm 2.0$ & $29.4 \pm 3.2$ & $29.0 \pm 1.5$ & $29.6 \pm 2.0$ \\
\hline & $10,000 \mathrm{mcds} / \mathrm{m}^{2}$ & $23.2 \pm 4.4$ & $23.8 \pm 4.0$ & $23.2 \pm 1.7$ & $22.8 \pm 1.3$ & $24.8 \pm 4.0$ & $23.8 \pm 1.3$ \\
\hline
\end{tabular}

Values are means $\pm \mathrm{SD} ; n=5$.

was noticed compared with those of the other groups $(P<$ 0.05 ), except the V1 group (Fig. 2). At day 5, 8/8 eyes were sterilized with LZD 30, whereas $7 / 8$ eyes were sterilized with V1 (Fig. 3). At day 8, a bacterial regrowth was noticed in a single eye of both the LZD 30 and the V1 groups.

Residual concentrations of linezolid, measured 24 hours after the intravitreal injection of linezolid, were $0.1 \pm 0.3,1.1$ \pm 0.6 , and $7 \pm 1.6 \mathrm{mg} / \mathrm{L}$ in the LZD 1 , LZD 10, and LZD 30 groups, respectively. The vitreous half-time of linezolid was calculated by the formula $(24 \times \log 2) / \log \left(C_{\max } / C_{24 h}\right)$. In consequence according to a first-order kinetics elimination, the linezolid estimated half-time in the vitreous was between 1.9 and 2.1 hours (Table 4).

\section{Histologic Analysis}

There was a significant difference in the histologic scores between groups ( $P=0.017$, Kruskal-Wallis test) (Fig. 4). Eyes from the LZD 30 and V1 groups possessed intact retinal architecture, and few inflammatory cells in the vitreous. Eyes from the LZD 10 group exhibited a mild to moderate inflammatory response in the anterior segment and the vitreous. Inflammatory cells and sometimes cocci were observed throughout the vitreous, but occurred in greatest numbers at vitreous interfaces and on the posterior surface of the ciliary body. Retinal architecture was disrupted, with retinal detachment, photoreceptor layer folding, and inflammatory cells located within the retinal layers. However, some normal retinal tissue was seen. Inflammatory cells were observed migrating from the vitreous into the retina (Fig. 5).
In general, these eyes were less inflamed than those of the LZD 1 group and from the BSS+ group. The LZD 1 and BSS+ groups exhibited severe inflammation in all parts of the eye. Inflammatory cells migrated in more significant numbers into the corneal periphery, forming a corneal ring abscess. Inflammatory cells, fibrin, and sometimes erythrocytes filled the anterior segment. Retinal structures were indistinguishable and the posterior chamber was filled with inflammatory cells and fibrin.

\section{Functional Analysis}

The scotopic single-flash ERG a- and b-wave amplitudes and implicit times are presented in Table 5. The eyes treated with LZD at a dose of $30 \mathrm{mg}$ did not display any modification in the ERG a-wave and b-wave amplitudes and latencies when compared with contralateral eyes under both dark- and lightadapted conditions. The ERG traces had a conventional aspect (Fig. 6). In scotopic conditions, a pure rod response was visible at $10 \mathrm{mcds} / \mathrm{m}^{2}$, whereas a mixed $\mathrm{rod} / \mathrm{cone}$ response was observed at $10,000 \mathrm{mcds} / \mathrm{m}^{2}$. The photopic cone ERG at $10,000 \mathrm{mcds} / \mathrm{m}^{2}$ was a standard cone response characterized by a pyramidal aspect and the presence of low-frequency oscillatory potentials on its top. When stimulated at $30 \mathrm{~Hz}$, retinas treated with LZD displayed well-individualized responses comparable to those of contralateral eyes under both scotopic and photopic conditions. The isolated oscillatory potentials did not reveal any difference between LZD-treated and contralateral eyes. 


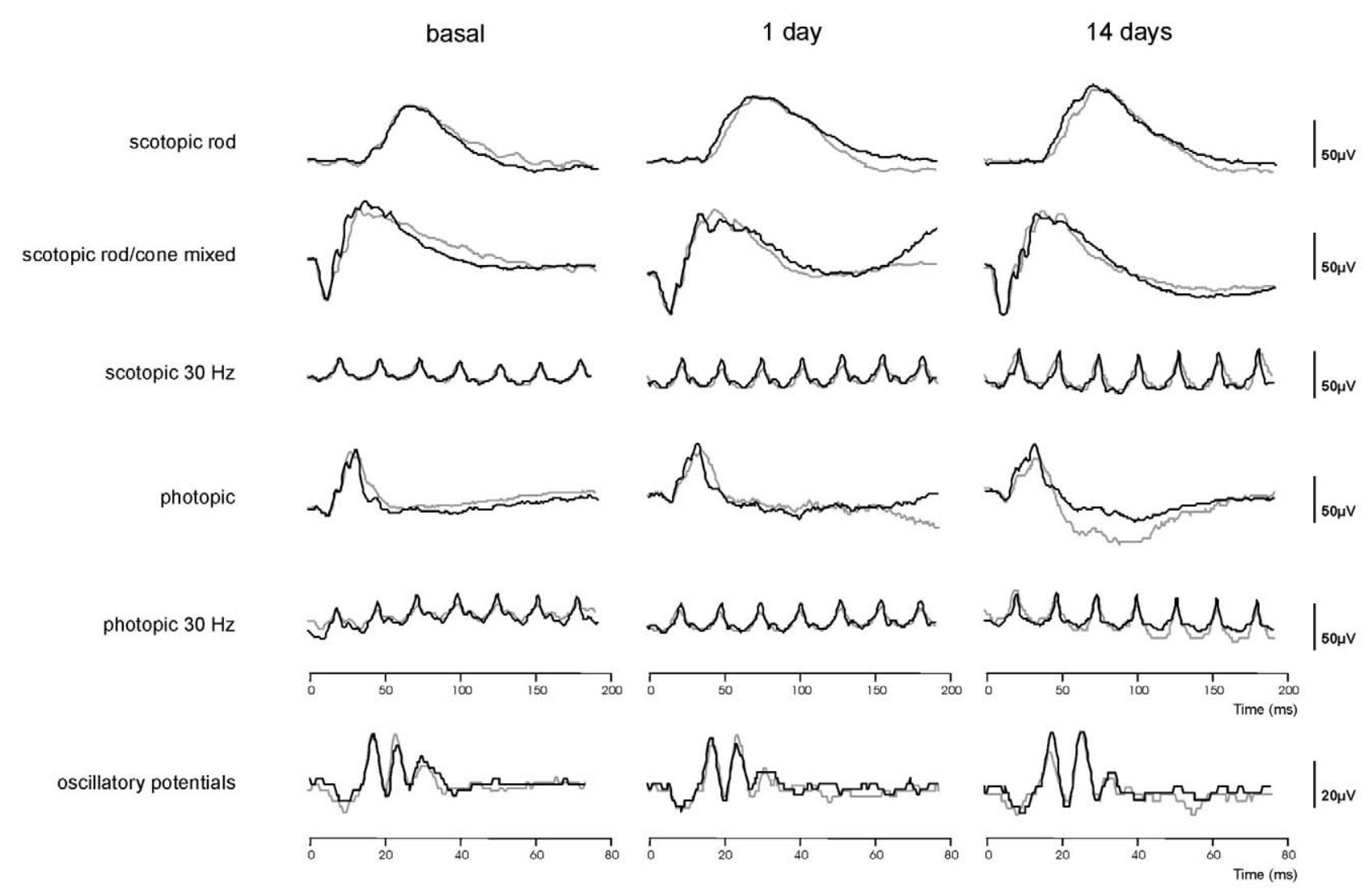

FIGURE 6. Time course of functional responses of rabbit eyes treated or not with LZD at a dose of $30 \mathrm{mg}$. The representative ERG traces did not show any difference in aspect between treated (gray traces) and contralateral (black traces) eyes in scotopic and photopic conditions after a singleflash stimulation or flicker stimuli.

\section{Discussion}

Linezolid remains a potent anti-Gram-positive antibiotic. The linezolid surveillance network ${ }^{25}$ confirmed that LZD retained excellent activity against monitored Gram-positive pathogens at a level of more than $99.6 \%{ }^{26}$ A study of the antibiotic susceptibility in bacteria isolated from human endophthalmitis also showed a linezolid susceptibility in $100 \%$ of coagulasenegative Staphylococcus ${ }^{27}$ and S. aureus. Therefore, linezolid was recently suggested as an alternative in the treatment of Gram-positive endophthalmitis. ${ }^{14,16,17}$ Previous pharmacokinetic studies have focused on the intraocular concentrations obtained by the systemic route, and it appeared that the maximal concentrations of linezolid after systemic administration were $6.8 \mathrm{mg} / \mathrm{L}$ in the aqueous humor and $5.7 \mathrm{mg} / \mathrm{L}$ in the vitreous. ${ }^{14,16,17}$ These concentrations were above the minimal inhibitory concentrations (MICs) of most causative bacteria $\left(\mathrm{MIC}_{90}=2 \mathrm{mg} / \mathrm{L}^{25}\right)$ and it was suggested that these levels could be sufficient to treat the Gram-positive-related endophthalmitis. However, there are no data available on the levels obtained after direct vitreal administration, which remains the best route of administration of antibiotics in this condition. Indeed, it is important to consider that the pharmacokinetic requirements for efficacy in bacterial endophthalmitis are more stringent compared with those for other tissues such as lungs or the skin because of the presence of a blood-ocular barrier. The best route to treat bacterial endophthalmitis remains the intravitreal route, because it shunts the blood-ocular barrier that limits the ocular penetration of antibiotics from the blood stream, providing intravitreal levels of antibiotics higher than those obtained after a systemic administration for protracted periods of time. ${ }^{4}$

Vitreous concentrations of LZD obtained by the vitreal route in this experimental model are considered high compared with the concentrations obtained in the serum after systemic administration. However, the failure of the 1 and 10 $\mathrm{mg}$ intravitreal LZD doses in sterilizing the staphylococcal endophthalmitis was surprising since the peak antibiotic levels $\left(\mathrm{C}_{\max }\right)$ were in all the groups several dilutions greater than the MIC for linezolid of the inoculated $S$. aureus $(\mathrm{MIC}=2 \mathrm{mg} / \mathrm{L}$ ) (Table 4). The failure to sterilize the eye could be partially explained by the fact that linezolid, which is considered as a time-dependent antibiotic, ${ }^{28}$ displayed a very short half-life in the vitreous. Indeed, its half-life in the inflamed eye was around 2 hours when vancomycin displays a half-time of more than 48 hours in the same conditions. ${ }^{29}$ This rapid clearance of linezolid from the vitreous could be related to the severe ocular inflammation associated with bacterial endophthalmitis that enhances the elimination of the drug from the ocular structures as it was previously demonstrated for other antibiotics (i.e., gentamicin ${ }^{30}$ or vancomycin ${ }^{29,31}$ ).

Pharmacodynamic parameters determining the efficacy of linezolid against $S$. aureus in the eye are not known. Most data on linezolid pharmacodynamics are based on serum concentrations and it is admitted that the $\mathrm{AUC}_{24} / \mathrm{MIC}$ ratio ${ }^{32}$ and $t>$ $\mathrm{MIC}^{33}$ are the most suitable parameters to predict the antistaphylococcal effect of linezolid. In our experimental model of endophthalmitis, $\mathrm{AUC}_{24} / \mathrm{MIC}$ did not appear to be predictive of antibacterial efficacy, since high ratios reached in the 1 and $10 \mathrm{mg} \mathrm{LZD}$ groups (respectively 3999.5 and 39,999.6 
$\mathrm{mg} / \mathrm{L} \cdot \mathrm{h}$ ) were not sufficient to provide a satisfactory bactericidal activity. Increasing doses of linezolid improved the bactericidal efficacy of linezolid in the eye. According to clinical, bacterial, and histologic criteria, the $30 \mathrm{mg}$ of linezolid was bactericidal and was at least as effective as the injection of the reference treatment, vancomycin, in curing the endophthalmitis. At this dose, linezolid was also superior to other regimens in preserving the architecture of the ocular structures, especially the retinal structure. Such a concentration-dependent killing of staphylococci exposed to linezolid has been already reported in an in vitro model. ${ }^{32}$ However, even if the gross anatomy was found to be intact, there are no data available on the toxicity of such doses of intravitreal linezolid on the retinal function. A study of the visual function, tested by electroretinography, after intravitreal injection of linezolid in the eyes of rabbits, was performed only at low doses of linezolid (up to $300 \mu \mathrm{g} / 0.1 \mathrm{~mL}$ ). ${ }^{34}$ It appeared that linezolid was well tolerated at these doses. It is not known if higher doses delivered in the vitreous could trigger visual dysfunction such as optic neuropathies that have been described in prolonged oral administration of linezolid. ${ }^{35}$

In our study, a $30 \mathrm{mg}$ dose of linezolid appeared to be safe for the retinal function, even 2 weeks after the intravitreal injection. Even if numerous ocular pharmacokinetic/pharmacokinetic (PK/PD) studies are conducted on rabbits because of the anatomic characteristics of the rabbit eye (i.e., globe size and aqueous humor turnover rate comparable to those of human eyes), caution must be taken before extrapolating these results to humans. One of the limitations of this study is the repeated punctures of the eyeball that could result in relative dilution of the antibiotic in the newly secreted aqueous humor and a breach in the blood-ocular barrier. However, the same procedure was performed in the vancomycin group, and it is likely that dilution occurred in the same proportion in both groups. To predict more accurately the parameter predictive of antibacterial efficacy, the relationship of the 24-hour ocular concentrations to the intensity of the antimicrobial effect should be explored in a dedicated study. These results emphasize the diversity of factors involved in antibacterial activity in vivo and stress the importance of animal models in complement to the in vitro spectrum of the antibiotic.

In conclusion, this study demonstrates the first evidence of the effectiveness of linezolid for the treatment of experimental staphylococcal endophthalmitis. High intravitreal levels are needed to ensure an acceptable bactericidal effect. Such intravitreal doses of linezolid appeared to be safe for the retinal function.

\section{References}

1. Han DP, Wisniewski SR, Wilson LA, et al. Spectrum and susceptibilities of microbiologic isolates in the Endophthalmitis Vitrectomy Study. Am J Ophthalmol. 1996;122:1-17.

2. Hanscom TA. Postoperative endophthalmitis. Clin Infect Dis. 2004;38:542-546.

3. Aaberg TM Jr, Flynn HW Jr, Schiffman J, Newton J. Nosocomial acute-onset postoperative endophthalmitis survey. A 10-year review of incidence and outcomes. Ophthalmology. 1998;105: 1004-1010

4. Results of the Endophthalmitis Vitrectomy Study. A randomized trial of immediate vitrectomy and of intravenous antibiotics for the treatment of postoperative bacterial endophthalmitis. Endophthalmitis Vitrectomy Study Group. Arch Ophthalmol. 1995;113:1479-1496.

5. Sakoulas G, Moellering RC Jr. Increasing antibiotic resistance among methicillin-resistant Staphylococcus aureus strains. Clin Infect Dis. 2008;46(suppl 5):S360-S367.
6. Miller D, Flynn PM, Scott IU, Alfonso EC, Flynn HW Jr. In vitro fluoroquinolone resistance in staphylococcal endophthalmitis isolates. Arch Ophthalmol. 2006;124:479-483.

7. Howden BP, Davies JK, Johnson PD, Stinear TP, Grayson ML. Reduced vancomycin susceptibility in Staphylococcus aureus, including vancomycin-intermediate and heterogeneous vancomycin-intermediate strains: resistance mechanisms, laboratory detection, and clinical implications. Clin Microbiol Rev. 2010; 23:99-139.

8. Weigel LM, Clewell DB, Gill SR, et al. Genetic analysis of a highlevel vancomycin-resistant isolate of Staphylococcus aureus. Science. 2003;302:1569-1571.

9. Benz MS, Scott IU, Flynn HW Jr, Unonius N, Miller D. Endophthalmitis isolates and antibiotic sensitivities: a 6-year review of culture-proven cases. Am J Ophthalmol. 2004;137: $38-42$.

10. Sharma S, Desai RU, Pass AB, Saffra NA. Vancomycin-resistant enterococcal endophthalmitis. Arch Ophthalmol. 2010;128: 794-795

11. Soriano F, Perez-Trallero E, Pallares R, et al. Streptococcus pneumoniae endophthalmitis: a study of 36 cases with special reference to antibiotic resistance and treatment options. Clin Microbiol Infect. 2006;12:519-526.

12. Wunderink RG, Rello J, Cammarata SK, Croos-Dabrera RV, Kollef MH. Linezolid vs vancomycin: analysis of two doubleblind studies of patients with methicillin-resistant Staphylococcus aureus nosocomial pneumonia. Chest. 2003;124:17891797.

13. Diekema DJ, Jones RN. Oxazolidinone antibiotics. Lancet. 2001;358:1975-1982.

14. Fiscella RG, Lai WW, Buerk B, et al. Aqueous and vitreous penetration of linezolid (Zyvox) after oral administration. Ophthalmology. 2004;111:1191-1195.

15. George JM, Fiscella R, Blair M, et al. Aqueous and vitreous penetration of linezolid and levofloxacin after oral administration. J Ocul Pharmacol Ther. 2010;26:579-586.

16. Prydal JI, Jenkins DR, Lovering A, Watts A. The pharmacokinetics of linezolid in the non-inflamed human eye. $\mathrm{BrJ}$ Ophthalmol. 2005;89:1418-1419.

17. Horcajada JP, Atienza R, Sarasa M, Soy D, Adan A, Mensa J. Pharmacokinetics of linezolid in human non-inflamed vitreous after systemic administration. J Antimicrob Chemother. 2009; 63:550-552.

18. Saleh M, Jehl F, Dory A, et al. Ocular penetration of topically applied linezolid in a rabbit model. J Cataract Refract Surg. 2010;36:488-492.

19. Nussenblatt RB, Palestine AG, Chan CC, Roberge F. Standardization of vitreal inflammatory activity in intermediate and posterior uveitis. Ophthalmology. 1985;92:467-471.

20. Park SS, Samiy N, Ruoff K, D'Amico DJ, Baker AS. Effect of intravitreal dexamethasone in treatment of pneumococcal endophthalmitis in rabbits. Arch Opbthalmol. 1995;113: 1324-1329.

21. Peyman GA, Paque JT, Meisels HI, Bennett TO. Postoperative endophthalmitis: a comparison of methods for treatment and prophylaxis with gentamicin. Ophthalmic Surg. 1975;6:4555.

22. Saleh M, Bourcier T, Prevost G, Speeg-Schatz C, Jehl F. Highperformance liquid chromatographic assay to measure linezolid antibiotic in eye tissues. Trends Chromatogr. 2008;4: $107-112$

23. Jaissle GB, May CA, Reinhard J, et al. Evaluation of the rhodopsin knockout mouse as a model of pure cone function. Invest Ophthalmol Vis Sci. 2001;42:506-513.

24. Creuzot-Garcher C, Acar N, Passemard M, et al. Functional and structural effect of intravitreal indocyanine green, triamcinolone acetonide, trypan blue, and brilliant blue $g$ on rat retina. Retina. 2010;30:1294-1301. 
25. Jones RN, Fritsche TR, Sader HS, Ross JE. Zyvox Annual Appraisal of Potency and Spectrum Program Results for 2006: an activity and spectrum analysis of linezolid using clinical isolates from 16 countries. Diagn Microbiol Infect Dis. 2007; 59:199-209.

26. Ross JE, Farrell DJ, Mendes RE, Sader HS, Jones RN. Eight-year (2002-2009) Summary of the Linezolid (Zyvox(R) Annual Appraisal of Potency and Spectrum; ZAAPS) Program in European Countries. J Chemother. 2011;23:71-76.

27. Harper T, Miller D, Flynn HW Jr. In vitro efficacy and pharmacodynamic indices for antibiotics against coagulasenegative staphylococcus endophthalmitis isolates. Ophthalmology. 2007;114:871-875.

28. Buchanan LV, Dailey CF, LeMay RJ, Zielinski RJ, Kuo MS, Gibson JK. Time-dependent antibacterial effects of linezolid in experimental rabbit endocarditis. J Antimicrob Chemother. 2002;50:440-442.

29. Park SS, Vallar RV, Hong CH, von Gunten S, Ruoff K, D'Amico DJ. Intravitreal dexamethasone effect on intravitreal vancomycin elimination in endophthalmitis. Arch Ophthalmol. 1999; 117:1058-1062.
30. Kane A, Barza M, Baum J. Intravitreal injection of gentamicin in rabbits. Effect of inflammation and pigmentation on half-life and ocular distribution. Invest Ophthalmol Vis Sci. 1981;20: 593-597.

31. Coco RM, Lopez MI, Pastor JC, Nozal MJ. Pharmacokinetics of intravitreal vancomycin in normal and infected rabbit eyes. $J$ Ocul Pharmacol Ther. 1998;14:555-563.

32. Strukova EN, Smirnova MV, Vostrov SN, et al. Linezolid pharmacodynamics with Staphylococcus aureus in an in vitro dynamic model. Int J Antimicrob Agents. 2009;33:251-254.

33. Andes D, van Ogtrop ML, Peng J, Craig WA. In vivo pharmacodynamics of a new oxazolidinone (linezolid). Antimicrob Agents Chemother. 2002;46:3484-3489.

34. Duke SL, Kump LI, Yuan Y, et al. The safety of intraocular linezolid in rabbits. Invest Ophthalmol Vis Sci. 2010;51:31153119.

35. Frippiat F, Bergiers C, Michel C, Dujardin JP, Derue G. Severe bilateral optic neuritis associated with prolonged linezolid therapy. J Antimicrob Chemother. 2004;53:1114-1115. 